\title{
Laboratorizing the wild rat (Rattus norvegicus)
}

\author{
ROBERT BOICE \\ University of Missouri, Columbia, Missouri 65201
}

Traditional difficulties in procuring wild rats can be overcome by trapping in an unstable environment (e.g., land-fill) where the natives do not fear strange objects such as traps. Techniques for trapping, transferring to, and maintaining in the laboratory are outlined, and apparatus for handling and housing, including the breeding situation, is described. Conclusion: Simple precautions render the wild rat nearly as easy to breed and use in conventional laboratory tasks as domesticated rats.

Animal psychologists work extensively with domesticated rodents, especially the albino rat, not without, however, persistent self-criticism over the assumed artificiality of the domestic rodent (Beach, 1950; Lockard, 1968, 1971). Consistent with this doubt is the unfounded, yet popular, assumption that the laboratory rat is degenerate and dull compared to his wily progenitor in the wild (Robinson, 1965). Two errors compound the misunderstanding: One is the belief that the question of the effect of domestication on learning ability is a closed matter; "There can be no doubt that differences between strains and between wild and domesticated rats have been found in a variety of learning situations ... [Lockard, 1968, p. 739]." The second is that the sole study of learning in wild and domesticated rodents (Stone, 1932) reported in Lockard's source (Robinson, 1965) has been misinterpreted to indicate that wild rats are superior performers. That study (Stone, 1932) actually showed that genetically wild rats perform erratically or not at all in a maze-learning situation. Superior performance was found with wild-laboratory rat hybrids, probably a result of heterosis. An early version of that comparison (Small, 1901) is even more inconclusive. While the erratic performance of the wild rats is easily dismissed as a "performance problem," the matter merits definitive research.

Another manifestation of psychology's inability to deal realistically with the question of rat domestication is comparisons of wild vs laboratory rats in which the wild rat is not the same species as the laboratory rat (Rattus norvegicus). Indeed, such studies manage to maximize our embarrassment to zoology by comparing rodents across families (e.g., Powell \& Morris, 1968; Eimer \& Senter, 1968).

Given that comparative psychologists recognize the value of research with the undomesticated Norway rat, the question is why it is not more common. One answer may lie in the almost mythical fear of the wild Norway rat-fear that it is frightfully gigantic ("as big as a cat"), ferocious, 1 diseased, and difficult to capture or maintain. None of these is apt. In fact, the wild Norway rat is usually smaller than the laboratory rat, actually less vicious than other rodents such as squirrels, rarely diseased, and reasonable to trap and maintain. Moreover, undomesticated rodents show interesting behavioral contrasts in behavioral conservativeness (Boice, 1968) and behavioral richness (Kavanau, 1967; Logan \& Boice, 1969), compared to domesticated rodents. One interesting conclusion from recent learning comparisons (e.g., Price, 1970) is that the domestic Norway rat is not a biologically degenerate descendent of its wild counterpart.

This paper, a collection of techniques from scattered literature and experience, is intended to show that laboratorizing the wild Norway rat is practical. This is, after all, the only direct way to determine effects of domestication on the domestic Norway rat. And knowledge of domestication mechanisms may have a larger scope, as man is often considered a domesticated animal (Richter, 1959; Eible-Eibesfeldt, 1970 ; Denny \& Ratner, 1970; Boice \& Shimk unas, 1971).

\section{COLLECTION TECHNIQUES}

The traditional literature on trapping Norway rats suggests difficulty. This may be because rats have traditionally been trapped from stable habitats where placement of any new object, such as a trap, elicits a strong neophobic avoidance reaction. Thompson (1948, 1953) and Chitty (1954) report lags of up to 10 days before capture and prescribe unvaried trap placement and prebaiting for success.

There is a readily available site in which the well-documented neophobia of wild Norway rats (Barnett, 1963) can be obviated. In the land-fill (a type of refuse dump) where trash is frequently bulldozed with layers of dirt, the indigenous rat cannot avoid new or human-scented objects and survive. A trap placed in such a situation does not elicit neophobia and captures are fast and representative of the population. Most captures occur within $15 \mathrm{~min}$, and within $4 \mathrm{~h}$ about $90 \%$ of all placements will likely result in a capture (e.g., Boice \& Boice, 1968). In contrast, I have had less than $5 \%$ success with placements left overnight in stable habitats, such as barns, ghettos, and packing/rendering plants. Other capture techniques, such as hand-netting, may also be used with success in areas where rats are plentiful. ${ }^{2}$ Following is a list of steps for trapping in a land-fill.

\section{Permission}

Most states require that anyone live-trapping for research obtain a scientific collector's permit via a conservation agency. This can be trying, since game management people are sometimes skeptical ${ }^{3}$ of psychologists, but it can prevent a costly fine. The city or county sanitation agent can usually suggest a good land-fill site. He can also help with administrative permission to visit the premises. Since some dumps are off limits to "pickers," scrap collectors, and target shooters, it is wise to inform police of nocturnal visits in advance. A good source of information regarding trap placements is the man who drives the bulldozer or manages the dump. He will be able to specify especially active areas and the recency of control efforts, including trapping and poisoning.

\section{Equipment}

Since placement is often in foul, even burning, refuse, a pair of rubber hunting boots is requisite. So is a good light for nocturnal visits, or at least until the captor habituates to the harmlessness of the situation. Wild rats do not attack a human intruder in this habitat. Any contact will be brief, as, for example, when a surprised rat runs over one's feet. This is, however, an indication of why boots should be worn over pants legs.

Traps of wire mesh (without solid walls) seem to work best. Havahart wire traps, at about $\$ 5$ each, have openings at both ends, are very well 
constructed and easy to use, but are not collapsible and are noisy in transport.

\section{Allcock Manufacturing \\ Box 551 \\ Ossining, New York 10563 \\ (914) 941-0121}

Folding wire traps, at $\$ 6-\$ 7$ each, are somewhat fragile but easy to transport. These lighter traps are available with single or double doors and as noncollapsible models.

National Live Trap Corporation

P.O. Box 302

Tomahawk, Wisconsin 54487

(715) 453-2249

Tomahawk Live Trap Company

P.O. Box 323

Tomahawk, Wisconsin 54487

(715) $453-3550$

Plans for rodent live-traps are plentiful (e.g., Richter \& Emlen, 1945; Chitty \& Kempson, 1949; Thompson, 1953), and new models appear occasionally in the Journal of Mammalogy. Baits with a salient odor, such as canned cat food or peanut butter, are quite effective, although even an unbaited trap will work where rats are highly active.

\section{Placement}

Every land-fill population of rats apparently has a somewhat unique pattern of activity, but generally speaking, sunset, midnight, and predawn are good times for trapping. Time of year is relevant only in that winter may increase a land-fill population when some rats withdraw from surrounding rural fields (Exrington, 1935). Even the hottest summer afternoons do not diminish activity, but care must be taken in this situation to prevent exposure to direct sunlight. Ten minutes of direct exposure is sufficient to be fatal. A simple solution is to cover the trap with a piece of cardboard or wood so as to shade it. Time of night may be relevant for trapping, since Calhoun (1962) found that social factors influence the activity periods of rats of differing social rank.

Baiting is especially effective if the trap has only one door opened so that the bait, on a piece of paper, can be localized behind the treadle. In this way, the rodent must step fully onto the treadle to get at the food. Food should not be placed so near the side of the trap that it can be reached from the outside. Sometimes leaving a slight trail of bait from its locus to just outside the door facilitates capture.

A critical step, upon arriving at the capture site, is watching for areas of activity. This may require standing silently for several minutes if the rats stop moving at the approach of an intruder. Even in a situation where the trash is moved daily, the rats will travel in somewhat specified areas, many of which will be under cover. Open travel areas, especially where food is already available, make excellent trap sites. Of course, removal of existing food, such as potato peelings or bread, further enhances success. Often, the best trapping areas are near active or smoldering fire in situations where the land-fill management "burns off" fresh dumpings. The rats do not avoid fire, even running through it or over hot ashes.

When traps are set, the trapper should withdraw from the immediate area, wait quietly until the rats resume activity, and listen for the traps to close. I usually wait a maximum of $2 \mathrm{~h}$ before leaving with all the traps; overnight settings are not advisable where early morning strollers abound. Traps are readily stolen, with even the most officious or ominous warnings attached.

\section{Taxonomic Identification}

In most land-fill sites captives will be exclusively Norway rats. Occasional exceptions, such as cats, present no problem of taxonomy, even for the psychologist. In situations where there is a possibility of collecting other rodents, some preparation in taxonomy is helpful.

The most likely source of confusion is between the congeners Rattus norvegicus (the Norway rat) and Rattus rattus (the black rat). This is somewhat simplified by the decreasingly limited geographical distribution of the black rat in this country. The black rat is now generally confined to the warm southern states and the Pacific coast (Brown, 1960), having been excluded by the relative newcomer, the Norway rat (Donaldson, 1924; Richter, 1954; Ecke, 1954). In areas where both species coexist, Rattus rattus (also called the roof rat) may be confined to the part of the habitat requiring climbing.

When the basic morphological differences between Rattus norvegicus and Rattus rattus are known, discrimination is not difficult. Brown (1960) diagrams the distinction between Norway rats, black rats, and a third Murid (Old World) rodent which shares the habitat and some physical characteristics of Rattus, the house mouse (Mus musculus). Barnett (1963, 1967 ) provides photographs and detailed drawings of the two Rattus species, as do numerous other writers. Briefly, $R$. rattus, compared to
$R$. norvegicus, has a longer tail (longer than head plus body), more pointed nose, larger eyes and ears, and 10 instead of 12 mammae. The house mouse could be confused with an immature rat, except that Mus has relatively small feet and head. A word of caution is directed to psychologists who tend to follow any zoological source blindly. Robinson (1965), for example, lists the rabbit as a rodent, but, on the other hand, he has compiled an impressively comprehensive review of studies on the Norway rat. One problem is that many zoologists are disinterested in and uninformed about Norway rats. Crandall's (1964) attitude is typical, as he notes of American Rattus: "Neither of these species is ordinarily exhibited by zoological gardens, energies more usually being devoted to elimination [p. 237]." Another problem is that the erroneous belief that Rattus rattus rather than Rattus norvegicus is the progenitor of the domesticated rat is even held by some prominent zoologists (Walker et al, 1964; Simpson, 1970). The truth comes from uncomplicated demonstrations: Crosses between the two species are not viable, crosses between black rats and laboratory rats are not viable, but crosses between Norway rats and laboratory rats are viable (e.g., Castle, 1947; Hiraiwa \& Yoshida, 1955).

All other rats which are captured in the United States will not be Murids and will have tails noticeably less naked and scaly than Rattus or Mus. Only three of the Cricetid (New World) rats are similar enough to cause confusion. Two of these, the cotton rat (Sigmodon) and the rice rat (Oryzomys), are Microtines, or small vole-like rodents, with short tails, coarse fur, nearly concealed ears, and a distribution limited to the southern part of the U.S. The third, the pack rats (Neotoma), have quite furry tails, a "clean" appearance relative to Murids, and build conspicious nests as a result of their collecting habits. A good field guide (e.g., Burt \& Grossenheider, 1964) provides illustrations and distribution maps for most American rodents. There is no indication in the literature that any of these New World rodents coexist with Rattus where the latter population is of high enough density to permit trapping for research.

\section{Health}

The wild Norway rat is remarkably hardy and, when raised in the laboratory, remarkably healthy. King (1939) found middle-ear infection to be almost nonexistent in 25 generations of captive Norway rats. The freshly trapped rat, however, is often the victim of a polluted 
environment, and his maladies merit concern. Rats from very smoky habitats may show extreme swelling of nasal tissue so that the muzzle is enlarged and squared, giving a dog-like appearance. Necropsy of rats from such habitats reveals congested and partially consolidated lungs. A more subtle problem is poisoning, frequently in the form of an anticoagulant. While refuse dump administrators can usually advise of poisoning, control programs are sometimes effected from other administrative units without notification between governmental levels. Recognition of poisoning is not difficult. Chronically intoxicated rats are, as a group, remarkably quiescent and nonaggressive in captivity until the condition diminishes. Chronic toxicity may be confirmed by renal and liver lesions. ${ }^{4}$ Surprisingly, either type of rat, with respiratory congestion or chronic toxicity, survives and eventually breeds in the laboratory as well as unafflicted captives. Calhoun (1962) presents a comprehensive analysis of health problems and mortality in the wild rat.

Barnett (1958) lists diseases of Norway rats which can be communicated to man. Scratching can cause Weil's disease (leptospiral jaundice), and rat bite fevers are a slight hazard, even from laboratory rats. More serious is salmonella poisoning from spoiled food, which produces severe diarrhea and death. Salmonella presents a serious threat to existing colonies of rodents, and a quarantine with a few albinos will help identify such a problem. It may be best to take initial specimens from a population to professionals, as in a veterinary diagnostic laboratory, for a necropsy. The plague, incidentally, is currently carried by fleas on a few rodents such as the prairie dog (Cynomys) but probably not on rats in this country. The best way to avoid contracting these uncommon rat diseases is to avoid direct handling of wild-caught rats. Practical means for mechanical transfer are discussed below.

In the long run, the important health question is whether to laboratorize rats with fresh wounds inflicted on the back and tail-base by conspecifics. Since such rats probably comprise the lower echelon of social status and do not seem to habituate or breed well in captivity, they might justifiably be excluded from collections.

\section{MAINTENANCE TECHNIQUES}

King's (1939) classic study of laboratorizing Rattus norvegicus over 25 generations is the traditional model of difficulty in maintaining undomesticated rats. She found rats in early generations to show a "high nervous tension and extreme fear of man," that they "ran wildly about the cage" when accustomed workers approached, and "constantly gnawed" their cages in "efforts to escape confinement." Moreover, King, as well as Richter (1949), found that few undomesticated rats were likely to mate successfully and that most mothers neglected or savaged their offspring. This discouraging picture has been tempered by recent research in which wild rats selected for an absence of scar-markings are easily $\mathrm{m}$ a i $\mathrm{nta}$ in ed a $\mathrm{nd}$ s ho w breeding/maternal success comparable to that of laboratory rats (Boice \& Boice, 1968).

\section{Handling}

Upon arrival in the laboratory, the captive is most efficiently transferred to a living cage, holding device, or weighed, by first dropping the rat from the trap into a bag. The bag should be wrapped tightly around the end of the trap as the door is remotely opened and should be allowed to hang mostly over the edge of the table. A vanishing-floor variation of this technique is described by Evans, Smart, \& Stoddard (1968). Most rats run into the bag instantly, others are tenacious holders and must be shaken into the bag. A large transparent bag of the sort that lines Wayne feed bags is as efficient as the traditional favorite, the flour sack, and affords visual monitoring of movement and identification of sex. Rats do not, incidentally, seem to attempt to bite through the bag or at the person holding the bag. 5 Transfer into cages and apparatus chambers is easiest when they have a sliding door; then the bag and rat can be inserted together, the door nearly closed, and the bag withdrawn through the narrow opening. A cone-shaped device developed by Emlen (1944) is invaluable in holding rats for examination or marking.

If adult captives must be handled, industrial gauntlets should be worn under gloves. Safety gloves of metal mesh are marketed for butchers but are effective in handling wild mammals, even primates.

\section{Whiting \& Davis Company \\ Plainville, Massachusetts 02762 \\ (617) 699-4411}

Several authors, including Barnett (1958) and Rasmussen (1939), have noted that wild rats can be tamed, especially if handling begins before weaning and is regular. Richard Millar, who is now completing a dissertation on the effects of handling upon performance of wild rats in learning situations, has had excellent success in taming the offspring of captives. Although his tamed rats remain somewhat reactive compared to laboratory rats, they can be handled without gloves. Indeed, the genetic variability is such that captives are occasionally encountered who are healthy and docile enough to be handled without taming. This great heterogeneity is, of course, a difference to be reckoned in comparison to commercial strains of rats.

A plastic handling box developed by Tighe (1965) is ideal for transfers between cage and apparatus. The box is placed directly over the rat, and its sliding floor elicits a minimal emotional response in the rat as he is nudged to step onto it.

\section{Housing}

The handling box is even more efficient if cages are made to allow a near-fit insertion of the box. Figure 1 shows an inexpensive, easily constructed cage for foolproof transfers; the interior dimensions slightly exceed the exterior dimensions of the handling box. This is simply a modification of the Wahmann-type hanging cage, with slots to accept a sliding door. The sides are exterior plywood (and varnished to resist urine) with slots to accept the sliding top, the floor is $1 / 4$-in.-mesh hardware cloth (1/8-in. mesh is appropriate where litters might be present), the top is Masonite, and the pieces of angle-aluminum are attached to coincide with the channels in a Wahmann cage rack. Marine spar varnish is probably the most durable variety and may be best for this application. Wild rats can chew through surfaces much harder than the plywood used in these cages, but since their incisors curve inward, they must have an edge on which to begin. This cage offers no such edges and thus it has endured. In the event that the wood is scratched and then chewed, the walls can easily be lined with hardware cloth. The wood does absorb some urine, but this is considered to be beneficial, since most rodents spend much time and effort "remarking" a cleaned cage. Thus, cage cleaning is not advised, except where disease or a new rodent is present.

Commercial rat cages with sliding doors are apparently not available, although Wahmann cages can be fitted with metal tops which slide over the flanges of the cage while allowing insertion of cage and top into the rack. Bussey cages work reasonably well with wild rats since the cages have covered tops. The front-opening model of Bussey rat cages offers the 


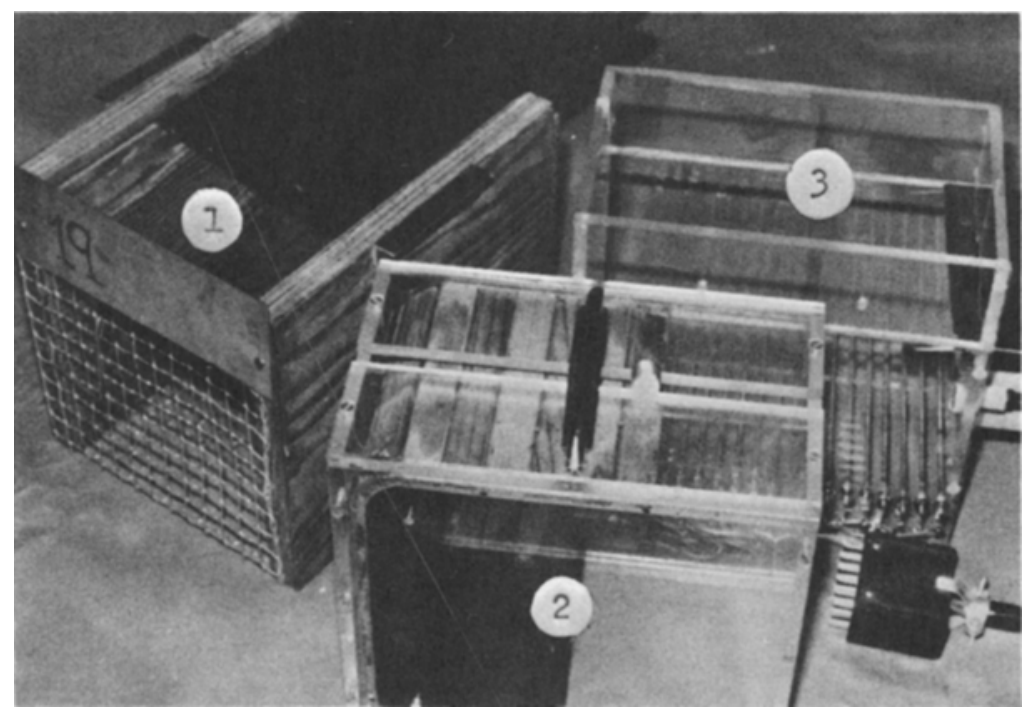

Fig. 1. The hanging individual cage (1), the plastic handling box with inside sliding door (2), and an operant chamber (with detachable plug) which can be used as a handling box (3). When the handling box is used, it is placed on the sliding top of the cage, the bent nail holding the top is removed, the top is slid out, and the handling box, with floor open, is placed over the rat. The operant chamber, which is also shaped to fit inside the cage, can be used for a more direct transfer when the cage is inverted over the chamber, allowing the rat to drop in.

advantage of the cage in Fig. 1; the handling box can be placed over the rat, forcing his removal from the cage.

\section{Bussey Products Company \\ 2700 West 35th Street \\ Chicago, Ilinois 60632 \\ (312) 847-5035}

Many wild rats will not leave their cage when the door is opened. For those that do, a fork-like device can be made to be inserted through the sides of the cage, just behind the door, until the transfer cage is in position. In the event that a rat does escape to the floor of the laboratory, simply place open live-traps next to the walls and chase the rat into one.

Some new captives will drink excessive amounts of water $(>1 \mathrm{cc} / \mathrm{g}$ body weight/day), but a moderate daily ration of about $50 \mathrm{cc}$ is sufficient to maintain good health and will diminish problems of maintenance and odor until the rats habituate to the laboratory. New captives from a refuse dump will be dirty and will smell of their former surrounds. They will, however, groom themselves into clean shape in a few days. The question of exposing new captives to spraying or dusting for fleas or even immersion in commercial dip is best the decision of the individual researcher since such techniques are obviously stressful to the rats. In spite of Richter's well-publicized accounts of new captives dying almost spontaneously, I have not seen a death from handling or spraying in hundreds of captives. Two exceptions occurred in running wild-caught rats in a conditioning apparatus where the $\mathrm{E}$ was an anxious premedicine student. After a 3-month stay in laboratory, wild-caught rats perform an avoidance response as well as laboratory-raised wild rats and clearly better than newly captured wild rats (Boice, 1970). Other, unpublished, data show a corresponding drop in measures of emotionality, such as respiration rate in response to close presence of $E$ by the third month of captivity.

Social housing of adult males should be limited to rats brought up together (Barnett, 1958) or to large cages with individual nest boxes.

\section{Breeding}

Breeding of wild rats can be effected in any laboratory cage, even without nesting material (Boice, 1966), although exposure of the pups to a metal surface may result in "ringtail" (Farris \& Griffith, 1942). Maternal success may, however, be enhanced by providing nesting material of cloth and cotton. Optimal

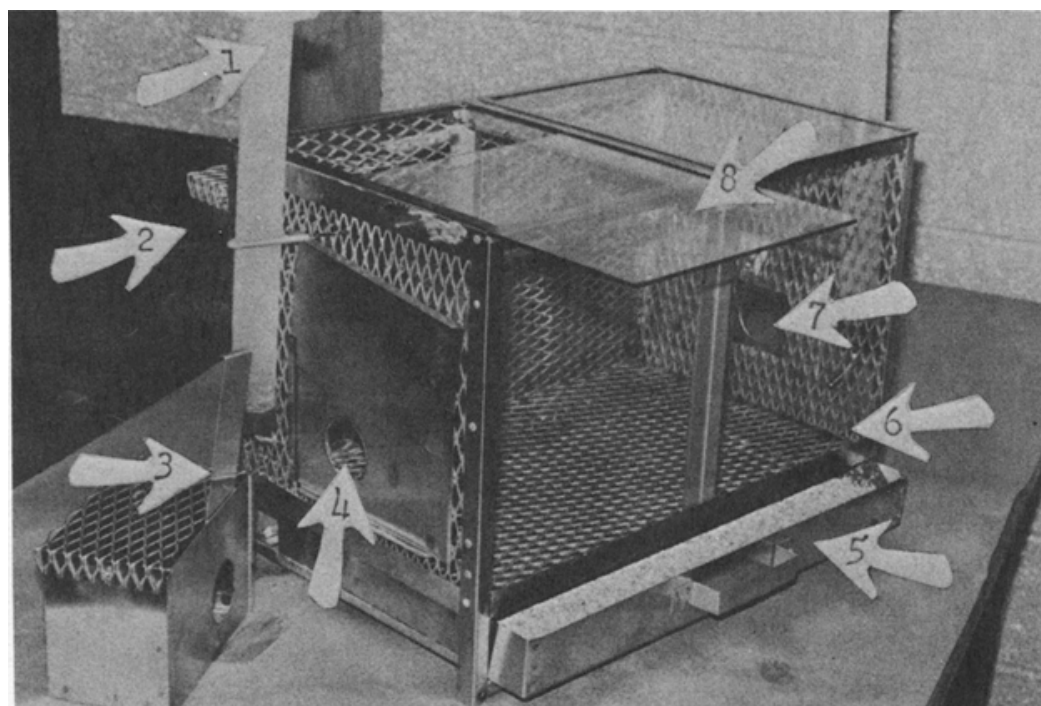

Fig. 2. The breeding cage with water cylinder (1), a rear nest box in place (2), a detached nest box with removable sliding door in jammed position (3), the bracket which holds that nest box and a replacement cover in jammed position (4), the wood-chip tray shown partly withdrawn (5), the removable glass front and the expanded stainless steel floor and sides (6), the closed entrance to a side nest box (7), and one of two glass sliding tops (8). An additional glass pane can be vertically inserted between the tops to divide the chamber. 
conditions for maternal behavior seem to include multiple nest boxes at and above ground level (Barnett, 1958) or in a burrow pattern (Marsh, 1968). Figure 2 shows a glass-fronted cage with expanded stainless steel sides and floor and removable nest boxes, designed for efficiency in producing litters and ease of observation and filming of social/maternal behaviors. Each nest box has a sliding door which allows the removal of a nest box with its inhabitant(s), a handy mechanism for rearranging the personnel of cages. Rats not already in a nest box can be induced to enter one by tapping on the glass or rattling the wood-shavings pan below them. Individual rats can likewise be induced to leave a nest by blowing directly at them through the holes in the top of the nest box. When a nest box is removed from the cage, the resultant opening in the cage is blocked by sliding a piece of metal into the channels which ordinarily hold the flanges of the nest box. I have chosen to use solid floors in the nest boxes, but this is optional as long as the mesh substitute is not so coarse as to permit the pups to fall through. In this situation, the mother builds a rather permanent nest (although new material should be provided regularly) which is "... often unsightly, and often looks unhygenic, but it evidently suits the rats [Barnett, 1958, p. 10]." Part of the syndrome of maternal behaviors in successful mothers, it should be added, is the careful removal of fecal material from the nest by the mother (Boice, 1966). There is no apparent need to remove the male when the litter is born, as he will be kept at bay by the female. The step of mating in the laboratory can be conveniently avoided by trapping for pregnant females in the field. These mothers show the same maternal success as those mated in the laboratory.

The essence of producing viable litters to weaning age may lie in selecting wild rats which are not of low social status in their native surrounds. Traditional studies of breeding wild rats (King, 1939; Richter, 1949; Barnett, 1958) may have employed mostly low-status rats since they may be the most likely to be captured from a stable habitat. Calhoun (1962) found the "... tendency of socially low-ranking rats to exhibit a reduced avoidance of traps is so characteristic that it forms a portion of the syndrome of abnormal behavior... [p. 88]" of outcasts, which includes nesting in unfavorable situations and forming nonreproducing aggregates. In the land-fill situation described earlier, sampling (i.e., trapping) of the population appears to be representative of all social levels.
Extensive observations in land-fills suggest that low-status rats can be identified by their scarred backs and tattered ears. Calhoun (1962) also presents data which support this idea. To test the assumption that low-status captives are unique in showing poor breeding and maternal success, one study (Boice, 1966) compared two breeding pairs with scar markings and four pairs without scar markings. The former produced only three litters in 2 years, with all 28 pups savaged or neglected shortly after birth. The latter, the unscarred rats, produced seven litters within 5 months, with no cannibalism and numerous exhibitions of maternal care (e.g., removing fecal matter from nests $h$ which appeared superior to that observed in control groups of albinos. Moreover, much of the intractibility and emotionality traditionally attributed to captive wild rats was confined to scarred captives in that study and in a more extensive but unpublished replication. I have extended this test to rats trapped from stable habitats, such as rendering plants, with the usual limited success in breeding and maternal behaviors. Not all such captives were clearly scarred, however, and my observations of social behavior in stable habitats are too limited to permit firm conclusions about the role of low social status. Nonetheless, Calhoun's observations of rats in a seminatural stable situation remain pertinent. The hypothesis about status and success in the laboratory needs extensive testing, but the important finding is that selected wild rats from land-fills can be bred in captivity as efficiently as domesticated albinos.

This is not to say that all the problems of maintaining and breeding undomesticated rodents are solved or simple, for, as Bitterman (1960) notes, the work of being a truly comparative psychologist is not for the impatient. Lane-Petter (1963), for example, describes an attempt to breed wild Mus in captivity which proved unsuccessful until an activity cage was provided. Without knowing of this literature, I made a similar discovery in attempting to breed $M u s$; success came only with individuals who had escaped their cages and could roam the lab freely. Thus, maintaining the undomesticated form of rodent requires more effort, inventiveness, and luck than does the commercial form. The rewards come in the discovery of new techniques and of a richer, more dynamic brand of rodent behavior. Speculation about the artificiality of the albino rat can only be substantiated with research on the wild Norway rat as it is laboratorized and, over generations, subjected to various domestication pressures.

\section{REFERENCES}

BARNETT, S. A. Laboratory methods for behavior studies of wild rats, Journal of the Animal Technicians Association, $1958,9,6-14$.

BARNETT, S. A. The rat: A study of behavior. Chicago: Aldine, 1963.

BARNETT, S. A. Rats. Scientific American, $1967,216,78-85$.

BEACH, F. A. The snark was a boojum. American Psychologist, 1950, 5, 115-124.

BITTERMAN, M. E. Toward a comparative psychology of learning. American Psychologist, 1960, 15, 704-712.

BOICE, $R$. The problem of domestication in the laboratory rat and a comparison of partially reinforced 'discriminatory' and anticipatory licking in domestic and wild strains of Rattus norvegicus. Doctoral dissertation, Michgian State University, 1966.

BOICE, R. Conditioned licking in wild $F$ and domestic Norway rats. Journal of Comparative Physiological Psychology, $1968,66,796-799$.

BOICE, $R$. The effect of domestication on avoidance learning in the Norway rat. Psychonomic Science, 1970, 18, 13-14.

BOICE, R.. \& BOICE, C. Trapping Norway rats in a land fill. Journal of the Scientific Laboratories, Denison University, 1968. 49, 1-4.

BOICE, R.. \& SHIMKUNAS, A. M. Domestication: What a beastly thing to do to man. Symposium chaired by the annual meeting of the Midwestern Psychological A ssociation. Detroit, 1971. BROWN, R. Z, Biological factors in domestic rodent control. Atlanta: U.S. Department of Health. Education and Welfare, 1960.

BURT, W. H. \& GROSSENHEIDER, R. P. $A$ field guide to mammals. Boston: Houghton Mifflin, 1964

CALHOUN, J. B. The ecology and sociology of the Norway rat. Bethesda: U.S. Department of Health, Education and Welfare, 1962

CASTLE, W. E. The domestication of the rat. Proceedings of the National Academy of Science, $1947,33,109-117$.

CHITTY, D. (Ed.) Control of rats and mice. Vol. I. Ox ford: Clarendon Press, 1954.

CHITTY, D., \& KEMPSON, D. A. Prebaiting small mammals and a new design of live trap. Ecology, 1949, 30, 536-542.

CRANDALL, L. S. The management of wild mammals in captivity. Chicago: University of Chicago Press, 1964.

DENNY, M. R.. \& RATNER, S. C. Comparative psychology. Homewood. Ill: Dorsey Press, 1970.

DONALDSON, H. H. The rat. Philadelphia: Wistar Institute, 1924

ECKE, D. H. An invasion of Norway rats in so uthwest Georgia. Journal of Mammalogy, 1954, 35, 521-525.

EIBLE-EIBESFELDT, I. Ethology. New York: Holt, Rinehart, \& Winston, 1970. EIMER, E. O.. \& SENTER, R. J. Alcohol consumption in domestic and wild rats. Psychonomic Science, $1968,10,319-320$

EMLEN, J. T. Device for holding live wild rats. Joumal of Wildlife Management. $1944,8,264-265$.

ERRINGTON, P. L. Wintering of field-living Norway rats in south central Wisconsin Ecology, 1935, 16, 122-123.

EVANS, C. S., SMART, J,L, \& STODDARD, R.C. Handling methods for wild house mice and wild rats. Laboratory Animals, 1968, 2, 29-34.

FARRIS, E. J., \& GRIFFITH, J. Q. (Eds.), The rat in laboratory investigation. Philadelphia: Lippincott, 1942.

HIRAIWA, Y. K., \& YOSHIDA, H. Conception in a cross between Rattus norvegicus and Rattus rattus. II. Breeding experiments using artificial insemination. Science Bulletin of the Faculty of Agriculture of Kyushu University, 1955 15. 267-273. 
KAVANAU, J. L. Behavior of captive white-footed mice. Science, 1967, 155 , 1623-1639.

KING, H. D. Life processes in gray Norway rats during fourteen years in captivity. American Anatomical Memoirs, 1939, 17, 1-22.

LANE-PETTER, W. The physical environment of rats and mice. In $W$. Lane-Petter (Ed.), Animals for research. London: Academic Press, 1963.

LOCKARD, $R$. B. The albino rat: A defensible choice or a bad habit? American Psychologist, 1968, 23, 734-742.

LOCKARD, R. B. Reflections on the fall of comparative psychology: Is there a message for us all? American Psychologist, 1971, 26, 168-179.

LOGAN, F. A., \& BOICE, R. Aggressive behaviors of paired rodents in an avoidance context. Behaviour, 1969, 34, 161-183.

MARSH, R. E. A colony box for rearing wild rats. Laboratory Animal Care, 1968. $18,639-641$.

POWELL, R. W., \& MORRIS, G. A comparison of escape and avoidance conditioning in wild and domesticated rats. Journal of the Experimental Analysis of Behavior, 1968, 11, 473-478.

PRICE, E. Domestication and early experience of effects on the acquisition and inhibition of a conditioned escape response by the Norway rat. American Zoologist, 1970, 10, 474.

RASMUSSEN, $E$. $W$. Wildness in rats: Heredity or environment? Acta Psychologica, 1939, 4, 295-304.

RICHTER, C. P. Domestication of the Norway rat and its implication for the problem of stress. Research Publications of the Association of Nervous and Mental Disease, 1949, 110, 379-386.

RICHTER, C. P. The effects of domestication and selection on the behavior of the Norway rat. Journal of the National Cancer Institute, 1954, 15, 727-738.

RICHTER, C. P. Rats, man, and the welfare state. American Psychologist, 1959, 14. 18-28.

RICHTER, C. P., \& EMLEN, J. T. A modified rabbit box trap for use in catching live wild rats for laboratory and field studies. Public Health Reports, $1945,60,1303-1308$

ROBINSON, R. Genetics of the Norway rat. Oxford: Pergamon Press, 1965.

SIMPSON, G. G, The penguin does not exist. Paper presented at the 78 th Annual Convention of the American Psychological Association, Miami Beach, 1970.

SMALL, W. S. Experimental study of the mental processes of the rat. II. American Journal of Psychology, 1901, 12 , 206-239.

STONE, $C, P$. Wildness and savageness in rats of different strains. In $K$. S. Lashley (Ed.), studies in the dynomics of behavior. Chicago: University of Chicago Press, 1932

THOMPSON, H. V. Studies of the behaviour of the common brown rat. 1. Watching marked rats taking plain and poison bait. Bulletin of Animal Behaviour, 1948, i(6), 26-40.

THOMPSON, H. V. Experimental live trapping of rats, with observations on their behaviour. British Journal of Animal
Behaviour, 1953, i, 96-111.

TIGHE, T. J. A handling device for small animals. Journal of the Experimental Analysis of Behavior, 1965, 8, 261-262.

WALKER, E. P. et al. Mammals of the world. Baltimore: Johns Hopkins Press, 1964.

\section{NOTES}

1. "If you have to capture and handle wild rats by yourself, be very careful because wild rats bite viciously and carry many diseases: almost a perfect contras with our tame, healthy rats." Personal communication from Jon Holtzman, Holtzman Company, 1965.

2. "We had no success in trapping in land fills, but we discovered a population of $\boldsymbol{R}$. norvegicus existing under circumstances such that we are highly successful in pursuing and netting them 'butterfly' style (we caught $60 R$. norvegicus in two four-hour sessions)." Personal communication from Donald $H$. Owings, University of Washington, 1968 .

3. In A thens, Ohio, conservation of ficials required that I be sponsored by a "real zoologist" before a collection permit was issued to me.

4. Case No.1691-70-In, Veterinary Medicine Diagnostic Laboratory, University of Missouri.

5. A reviewer for this journal notes that ". . wild Norways will bite through a bag. Perhaps my use of the bag has differed when they are in the bag, one can hold them dorsally, then move them up through the mouth of the bag for sexing or other inspection. Some bite." 